\title{
The Simulation of Fires in Underground Parking Floors by Fire Dynamic Simulator
}

\author{
Ming-Wen Hsu, ${ }^{*}$ Shin-Ku Lee, ${ }^{1}$ Lin-Lin Huang, ${ }^{2}$ Yaw-Kuang Chen, and Chun-Mu Wu ${ }^{3 * *}$ \\ Department of Architecture, National Cheng-Kung University, Tainan, 701, Taiwan, R.O.C. \\ ${ }^{1}$ Research Center for Energy Technology and Strategy, National Cheng-Kung University, Tainan, 701, Taiwan, R.O.C. \\ ${ }^{2}$ Department of Architecture and Interior Design, Cheng Shiu University, Kaohsiung 833, Taiwan, R.O.C. \\ ${ }^{3}$ Department of Mechanical Engineering and Automation Engineering, Kao Yuan University, \\ Kaohsiung 821, Taiwan, R.O.C.
}

(Received August 30, 2016; accepted January 12, 2017)

Keywords: underground parking floor, FDS, smoke ventilation system

Traffic flow in cities is increasing rapidly as cities modernize. The problem of parking is getting worse and worse due to insufficient parking lots in large cities, and people are paying more attention to safety issues in buildings due to the development of underground parking floors. There are new problems for fire safety because a building's functions and materials, structural type, size, and supporting facilities are very different between the traditional buildings and buildings with underground parking floors. When a fire occurs in an enclosed underground parking floor, it is hard for people to evacuate due to incomplete combustion producing heavy smoke. In this work, we use the Fire Dynamic Simulator (FDS) to study the effect of a mechanical smoke ventilation system to retard the development of a smoke layer. The simulated results indicate that, although the installation of a mechanical smoke ventilation system would retard the deposition of a smoke layer, fresh air also drawn in increases the heat release rate of a car fire. Most importantly, a mechanical smoke ventilation system can extend the escape time for people during the initial stages of a fire.

\section{Introduction}

With accelerating urban modernization and development of the automobile industry, the quantity and volume of traffic due to automobiles and motorcycles in cities increases continuously. The parking difficulties resulting from insufficient parking facilities has become increasingly severe in the large cities of Taiwan. The unsustainable growth of parking demand and relatively insufficient supply of parking facilities have brought a series of problems to urban development, such as traffic jams resulting from vehicle parking, traffic volume resulting from looking for a parking space, environmental pollution resulting from slow running while looking for parking. This parking issue has become a bottleneck that obstructs the further development of the national economy. Therefore, some large cities have actively developed public underground parking buildings and aerial parking for busy areas with insufficient land resources. As these underground parking buildings are very different from traditional architecture, building materials, structural style, size, and supporting facilities, they cause many new problems for fire safety.

"Corresponding author: e-mail: hmw6789@yahoo.com.tw

${ }^{* *}$ Corresponding author: e-mail: wtm@cc.kyu.edu.tw

http://dx.doi.org/10.18494/SAM.2017.1525

ISSN 0914-4935 C MYU K.K. 
The annual fire accident rate in parking lots increases with their annual usage. For this research, 5 fire accidents occurring in underground parking floors have been collected from the literature. The descriptions are as follows: On February 12, 2007, the underground parking in a 23-story amalgamated building in Taichung City suffered a fire at about 6 p.m., in which one man died and two persons had slight smoke inhalation. The field firemen connected smoke exhaust fans to the smoke extraction pipes to extract the dense smoke from the basement. On March 27, 2014, the basement of a building in Taipei City suffered a fire, and a conflagration broke out at the scene while the fire department was rescuing people. Five firemen were injured and sent to the hospital, and the 36 year old team leader of Huashan Station lost his life while being transported to the National Taiwan University Hospital. On June 27, 2014, the underground parking in an amalgamated building in New Taipei City raised a fire alarm at 9:45 p.m., and the local fire bureau sent out rescue personnel; according to the report, a fireman went downstairs to search for the origin of the fire and any persons in trouble and experienced serious choking when he inhaled too much high temperature dense smoke. Although he was sent to the hospital, the firefighter died. At about 7:45 a.m. on November 20, 2014, in the underground parking area of the legislator research building of the Legislative Yuan, a white BMW car began to smoke and caught fire, and although 6 or 7 fire extinguishers were emptied, the fire was not extinguished and the dense smoke obstructed escape. On March 22, 2015, a fire broke out in the underground parking lot of a 7-story apartment building in Tainan City, and one woman died. In recent years, underground fires have caused many casualties among firemen. Whether by accident or arson, most automobile fires are caused by fire in the engine bay. To extinguish such a fire, the engine hood must be opened, and other oils may ignite, causing the fire to spread. When untrained people try to extinguish a fire by themselves, they may miss the opportunity to escape, especially from within the confines of an underground parking facility, as the parked vehicles make the fire and smoke difficult to control; such dense smoke may result in poor visibility within a few minutes, and if the fire extinguisher fails to effectively extinguish the fire, the medium from the fire extinguishers will accelerate the effect of the fire; when extinguishing fails and they attempt to escape, the diffused extinguishing medium may obstruct their escape. In addition, dense smoke may obstruct the firemen's ability to search for survivors and the origin of fire. An effective layout of mechanical smoke vents is very helpful for people's escape and firemen's ability to rescue, and when combined with automatic fire sprinklers or fire or smoke compartments, they may augment the efficiency of fire protection for the entire underground parking space.

The most combustible items in underground parking areas are automobiles, which consist of complex parts composed of inflammable oils (e.g., gasoline and engine oil), foam, rubber, batteries, and plastics; thus, when a fire occurs, it spreads quickly and produces a great deal of dense smoke. There are numerous causes for vehicle fires, and the common conditions are described as follows:(1) (1) Fuel system leak

The flash point of 95 unleaded gasoline is $-43--38^{\circ} \mathrm{C}\left(-45--36^{\circ} \mathrm{F}\right)$, and the self-ignition temperature is $280-456^{\circ} \mathrm{C}\left(536-853^{\circ} \mathrm{F}\right)$; the flash point of diesel oil is $>52^{\circ} \mathrm{C}\left(>125.6^{\circ} \mathrm{F}\right)$, and the self-ignition temperature is about $177^{\circ} \mathrm{C}\left(351^{\circ} \mathrm{F}\right)$. The data show that a flash fire may occur if fuel vapor contacts a spark; for example, the high temperature of an exhaust pipe is sufficient for even diesel oil fuel to initiate a mass fire in such cases.

(2) Wire sparking or electrical faults

Like residential fires, many underground parking fires are caused by a sparking wire instead of a gas leak. The electric wiring in vehicles is aged by long-term over-heating, even though 
the material is more resistant to heat than general household wire. The storage battery is another problem; if the charge/discharge condition is poor or a poor storage battery is used, the storage battery may explode.

(3) Lubricating oil leak in an engine bay

A part of the leaking vehicle phenomena results from long-term aging, and part results from faults. While engines leaking oil and transmission fluid are most frequently seen, the oil for power steering, brake fluid, and gasoline/diesel oil may also leak. Basically, such oil products usually leak from the spacer or oil seal; however, leaks most frequently occur in the engine bay. Many people may not know that cooling fluid leaks may cause fire as well, because the cooling fluid contains a large amount of ethylene glycol, which is inflammable. In addition, some of these oils are comburent, especially the requisite gasoline/diesel oil for engine combustion, which is the optimum combustible, and if it leaks, serious hazards arise. These hazards include the design of the system, as the gasoline/diesel oil pipes in many vehicles go through the front and rear ends of a vehicle at the bottom.

(4) Engine overheating

The automobile engine is a large metal block which does not burn. There is only one cause for an engine to overheat: poor heat radiation. There are many causes for poor heat radiation, such as cooling tank faults, cooling fan faults, and coolant loss; however, the cooling system is usually the cause. Incomplete combustion is also a cause, where unburnt gas continues to burn in the exhaust manifold, resulting in high temperatures. When the engine is overheated, and as the catalytic converter is overheated, the peripheral comburents reach the combustion temperature and burn. In addition, there are more peripheral components than the catalytic converter, such as the many wires, joints, plastic containers, plastic pipes, oils, and fuel pipes around an engine, which all age with high temperature and may melt due to excessive temperature. Some components are combustible after they are molten, while some liquids are comburent after they leak (e.g., engine oil).

(5) Catalytic converter overheating

For the current internal combustion engine-based vehicles, the exhaust system is equipped with a catalytic converter, which has the basic function of oxidizing the $\mathrm{HC}, \mathrm{CO}$, and $\mathrm{NO}_{x}$ in the exhaust system into water and $\mathrm{CO}_{2}$, and reducing part of the $\mathrm{NO}_{x}$ to nitrogen. As the catalytic converter must convert $\mathrm{HC}, \mathrm{CO}$, and $\mathrm{NO}_{x}$ simultaneously, it is also known as a three-way catalytic converter. In a general manner, the operation of a catalytic converter requires a fixed temperature range, and it will become overheated if forced to work in a high temperature range for a long time, thus constituting the heat source for a fire. If the converter exists in an overheated operating range for a long time, there is probably a problem with the combustion efficiency of the engine.

(6) Arson

Cases of arson, which may be arise from emotion or money, are often seen on the news. Arson is unlike the indirect or direct factors of vehicles seen in the previous cases; its burn is the fastest, the least preventable, and it usually results in property loss and casualties.

A fire in an underground parking space behaves as follows: "the environmental space opening is limited and confined; lighting is insufficient; the smoke is difficult to exhaust, control, or extinguish"; "the outside air supply is limited; incomplete combustion may produce a great deal of dense smoke, especially when burning cables and wires produce toxic gas, obstructing those inside from escaping and firemen from rescuing"; "as the space is confined, heat radiation and smoke extraction are difficult, high temperature is likely to cause the fire scene temperature to rise rapidly, thus obstructing the initial rescue and escape, which may cause heavy casualties and evolve into a severe disaster". (2) 
Chen indicated that "underground buildings" include basements, underground streets, and underpasses and that the structures of underground buildings are very similar to confined highrise buildings. Therefore, an underground building fire has similar features to a high-rise fire. ${ }^{(2)}$ Underground parking is a type of basement, and its characteristics are classified as follows:

1. The fire scene is reached through stairs or a lift during fire rescue.

2. When an underground building is on fire, it is filled with dense smoke and toxic gases, because there are fewer openings on the underground floor, the air is insufficient, and fire is more likely to produce a great deal of dense smoke.

3. The heat cannot dissipate; the storage of heat certainly leads to high temperatures. As the underground area of a building is completely confined, the fire temperature is often higher than $1000^{\circ} \mathrm{C}$.

4. The fire spreads upward rapidly in an underground building, and once an underground floor is on fire, the floors under the ground floor are in immediate danger.

5. It is difficult to escape from an underground building, the underground floor is dark, and with the obstruction of compartments, passages, doors, or other space, it is very difficult to escape, and in the dense smoke and high heat, life is endangered in a short time.

6. It is very difficult to carry out a rescue from underground buildings when an underground floor has a high temperature. Because the rescuers must carry respirators, they cannot remain underground for long. In addition, it is dark, difficult to judge the extent of the combustion, and effective protection cannot be adopted.

In addition to the features similar to a high-rise fire, underground parking has the following special characteristics:

1. The underground building fire scene changes from time to time.

2. The rescue work is dangerous.

3. It is difficult to find the origin of the fire.

4. It is difficult to understand the fire's development;

Chung and $\mathrm{Chiu}^{(3)}$ described the characteristics of underground building spaces (including underground parking spaces):

1. As the opening into the space is limited and confined, it is difficult to perceive the internal condition of the underground building space from aboveground; it is difficult to know the ground conditions in an underground building.

2. Underground buildings have complex structures, and the fire scene changes quickly, presenting a very unstable state.

3. It is difficult to find the fire's origin and control its behavior in an underground building, firemen's rescue is likely to be limited by the distance between the gateway and the origin of the fire, and the path and space leading to the fire cannot contain too many rescue personnel or equipment, or reinforcement will be restricted.

4. As underground building spaces are without windows or are confined spaces without open floors, the outside air supply is restricted. Thus, due to the insufficient air for a fire, combustion will remain in the smoldering state, rendering the problem of dense smoke more severe, especially in a fire of smoke-producing materials, such as cables and electrical equipment.

5. If the underground space is connected to other facilities, wherever a fire breaks out, it may spread to the other side.

6. The water jetted by an automatic fire-extinguishing system or a firemen's hose is likely to accumulate, thus obstructing rescue and escape, and resulting in heavy water damage and loss. 
Zhang et al. ${ }^{(4)}$ simulated fire spread and fume flow in a simulated underground parking lot, and the fire spread rate and flow of smoke were observed under different ventilation conditions by setting the same automobile fire heat release rate. The plume in the parking space was very disorderly at $15 \mathrm{~min}$, and the fire behavior was expanded, making rescue and escape difficult. Merci and Shipp ${ }^{(5)}$ discussed the effect of smoke and temperature on an underground parking lot, smoke extraction by mechanical ventilation, and the dynamics of smoke and heat. The condition of spray sprinklers was input into the probable result, and the probabilities were studied. Deckers et al.(6) tested fume control in a large-scale motor park using computational fluid dynamics (CFD) software to simulate the effect of mechanical smoke extraction on the fume and found that, if the smoke was stuck in the recirculation zone, even if the smoke extraction rate was increased, it was impossible to eliminate the smoke layer.

In this study, we use the Fire Dynamic Simulator (FDS) to observe the generation time and range of dense smoke in an underground parking fire and discuss a mechanical smoke extraction system to study how to postpone the smoke layer generation time and prevent a disaster from developing further.

\section{Methodology}

\subsection{Basic theory and governing equation of FDS}

This study uses FDS 6.0 to build the experimental model and discusses smoke movement, the fire heat release rate, and smoke height in an underground parking floor fire. The characteristics of FDS 6.0 are described as follows: $:^{(7,8)}$

FDS is a field-based fire simulation software developed by the Building and Fire Research Laboratory, National Institute of Standards and Technology (NIST). It is a CFD model, which takes the fluid motion in a fire as the main model object. The results of calculations are processed by post-processing software (Smokeview), with which the plume, gas temperature distribution, and flow field distribution in the fire scene are displayed in animation, the fire scenario can be established rapidly, and the fire scene information can be known in time. The process structure and file format of FDS and Smokeview are shown in Fig. 1.

FDS is a special computational fluid dynamics software using 3D numerical calculation to simulate the air flow driven by fire buoyancy. The core of the software is the Navier-Stokes equation set. The equations are described, as follows:

1. Mass conservation equation

$$
\frac{\partial \rho}{\partial t}+\nabla \cdot \rho u=0
$$

$\rho$ : fluid density $\left(\mathrm{kg} / \mathrm{m}^{3}\right)$

$u$ : fluid air velocity $(\mathrm{m} / \mathrm{s})$

2. Momentum conservation equation

$$
\rho\left[\frac{\partial u}{\partial t}+(u \cdot \nabla) u\right]+\nabla p=\rho g+f+\nabla \cdot \tau
$$




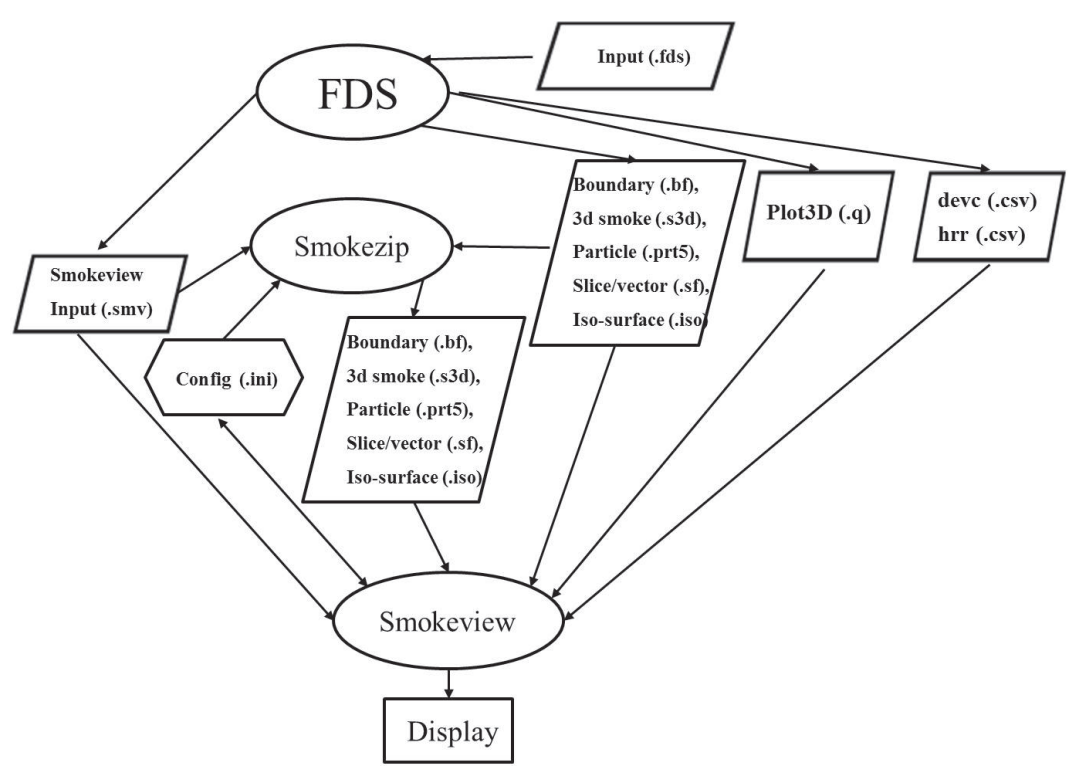

Fig. 1. Organizational structure and simulation computing process of FDS and Smokeview.

$p$ : pressure $(\mathrm{Pa})$

$f$ : external force term, including friction $(\mathrm{N})$, resulting from water droplets sprayed from the sprinkler head

g: gravity + air velocity $\left(\mathrm{m} / \mathrm{s}^{2}\right)$

$\tau$ : viscous stress tensor

3. Energy conservation equation

$$
\frac{\partial}{\partial t}(\rho h)+\nabla \cdot \rho h u=\frac{D p}{D t}-\nabla \cdot q_{r}+\nabla \cdot k \nabla T+\sum_{l} \nabla \cdot h_{l} \rho D_{l} \nabla Y_{l}
$$

$h$ : entropy $(\mathrm{J} / \mathrm{kg})$

$k$ : thermal conductivity $(\mathrm{W} / \mathrm{m} \cdot \mathrm{K})$

$T$ : temperature $(\mathrm{K})$

$D_{l}$ : diffusion coefficient $\left(\mathrm{m}^{2} / \mathrm{s}\right)$

$Y_{l}$ : mass fraction of species $l$

4. Species conservation equation

$$
\frac{\partial}{\partial t}\left(\rho Y_{l}\right)+\nabla \cdot \rho Y_{l} u=\nabla \cdot(\rho D)_{l} \nabla Y_{l}+\dot{m}_{l}^{\prime \prime \prime}
$$

$m_{l}^{\prime \prime \prime}:$ mass production rate per unit volume of species $l$

5. Ideal gas equation

$$
p=\rho R T
$$


The FDS classifies the temperature, density, and pressure into spatially averaged quantities and perturbations according to the Boussinesq approximation equation, which is expressed as follows:

$$
\begin{gathered}
T=T_{0}(t)(1+\tilde{T}) \\
\rho=\rho_{0}(t)(1+\tilde{\rho}) \\
p(\boldsymbol{r}, t)=p_{0}(t)-\rho_{0}(t) g z+\tilde{p}(\boldsymbol{r}, t)
\end{gathered}
$$

The spatially averaged quantity can be expressed by Eqs. (1), (2), and (5), and the adiabatic process is as follows:

$$
\begin{gathered}
p_{0} \int_{\partial \Omega} \boldsymbol{u} \cdot d \boldsymbol{S}+\frac{V}{\gamma} \frac{d p_{0}}{d t}=\frac{\gamma-1}{\gamma}\left(\int_{\Omega} q d V+\int_{\partial \Omega} k \nabla T \cdot d \boldsymbol{S}\right) \\
p_{0}=\rho_{0} R T_{0} \\
\frac{\rho_{0}}{\rho_{\infty}}=\left(\frac{p_{0}}{p_{\infty}}\right)^{\frac{1}{\gamma}}
\end{gathered}
$$

The perturbation of velocity, temperature, and pressure can be expressed as:

$$
\begin{gathered}
\frac{\partial \tilde{T}}{\partial t}+\boldsymbol{u} \cdot \nabla \tilde{T}=(1+\tilde{T})\left(\nabla \cdot \boldsymbol{u}+\frac{d p_{0}}{d t}\right) \\
\frac{\partial \boldsymbol{u}}{\partial t}-\boldsymbol{u} \times \omega+\nabla H=\frac{1}{\rho}\left[\left(\rho-\rho_{\infty}\right) \boldsymbol{g}+\boldsymbol{f}+\nabla \cdot \tau\right] \\
\nabla^{2} H=-\frac{\partial(\nabla \cdot \boldsymbol{u})}{\partial t}-\nabla \boldsymbol{F}
\end{gathered}
$$

where $H$ is the total pressure,

$$
\begin{gathered}
H=\frac{\tilde{p}}{\rho_{0}}+\frac{|\boldsymbol{u}|^{2}}{2} \\
\boldsymbol{F}=-\boldsymbol{u} \times \omega-\frac{1}{\rho}\left[\left(\rho-\rho_{\infty}\right) \boldsymbol{g}+\boldsymbol{f}+\nabla \cdot \tau\right]
\end{gathered}
$$

To sum up, FDS uses the energy equation, Eq. (13), the momentum equation, Eq. (14), the total pressure equation, Eq. (15), and the spatial average temperature, density, and pressure equations, Eqs. (9)-(11), to compute the velocity, temperature, density, and pressure of the computational domain. In terms of the numerical method of the governing equation, FDS uses the second-order central difference method for the derivative term of space coordinates and uses the dominant second-order Runge-Kutta method to discretize the derivative term of time. The total pressure differential equation in the Poisson equation form is computed directly using fast Fourier transform. 


\subsection{Underground parking fire model setting}

The subject selected for simulation in this study is a one-story underground parking lot, which is $36 \mathrm{~m}$ wide, $36 \mathrm{~m}$ long, and $3 \mathrm{~m}$ high. A two-way entrance-exit is located on both the left and right, and the lane is at the bottom left corner. There are 21 cars parked in the parking lot. Each car is $4.6 \mathrm{~m}$ long, $1.9 \mathrm{~m}$ wide, and $1.4 \mathrm{~m}$ high. The inflammable materials are set as gasoline and a foaming substance, and there are three fire origins in this study. The first fire origin is set as the first car on the upper left; the second fire origin is set as the first car on the left of the lower row; the third fire origin is set as the first car on the right of the lower row (labeled in red in Fig. 2). There are six smoke height monitoring points shown in Fig. 3. The smoke height is estimated from a continuous vertical profile of temperature. The $\operatorname{method}^{(9,10)}$ is described as follows: Consider a continuous function $T(z)$ defining temperature $T$ as a function of height above the floor $z$, where $z=$ 0 is the floor and $z=H$ is the ceiling. Define $T_{u}$ as the upper layer temperature, $T_{l}$ as the lower layer temperature, and $z_{\text {int }}$ as the interface height. Compute the quantities:

$$
\begin{gathered}
\left(H-z_{\text {int }}\right) T_{u}+z_{\text {int }} T_{l}=\int_{0}^{H} T(z) d z=I_{1} \\
\left(H-z_{\text {int }}\right) \frac{1}{T_{u}}+z_{\text {int }} \frac{1}{T_{l}}=\int_{0}^{H} \frac{1}{T(z)} d z=I_{2}
\end{gathered}
$$

Solve for $z_{\text {int }}$ :

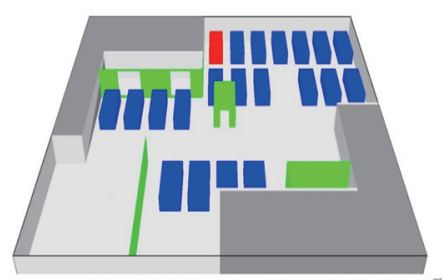

(a)

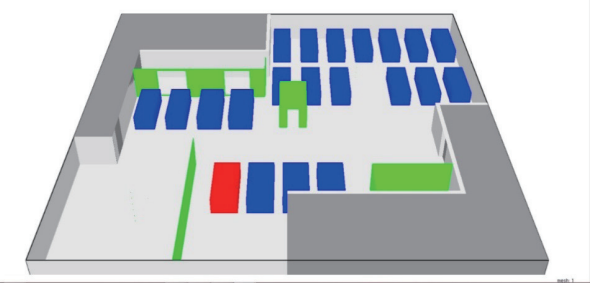

(b)

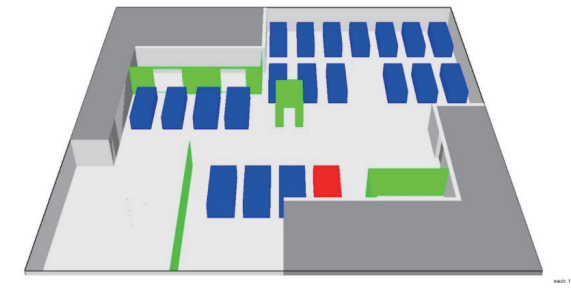

(c)

Fig. 2. (Color online) The fire ignition locations defined in this study.

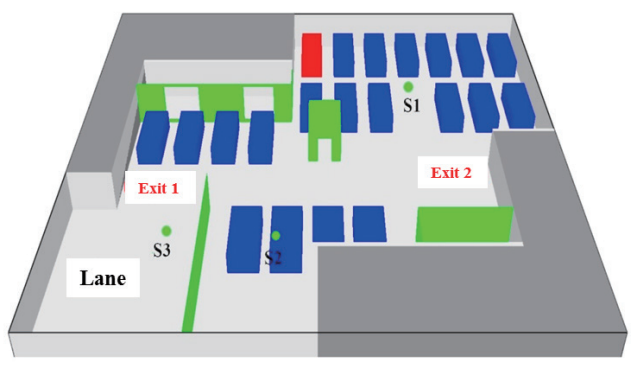

(a)

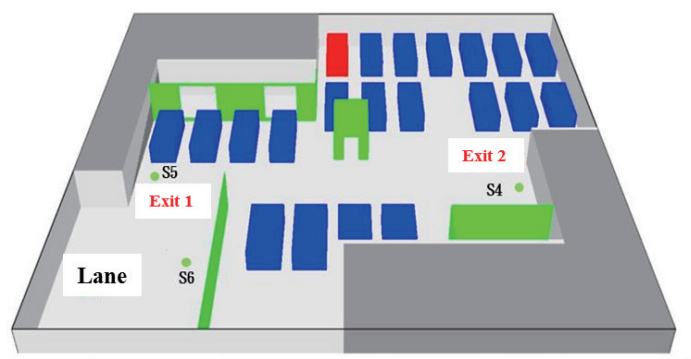

(b)

Fig. 3. (Color online) Location of smoke height monitoring systems. 


$$
z_{\text {int }}=\frac{T_{l}\left(I_{1} I_{2}-H^{2}\right)}{I_{1}+I_{2} T_{l}^{2}-2 T_{l} H}
$$

Let $T_{l}$ be the temperature in the lowest mesh cell and, using Simpson's Rule, perform the numerical integration of $I_{1}$ and $I_{2} . T_{u}$ is defined as the average upper layer temperature via

$$
\left(H-z_{\text {int }}\right) T_{u}=\int_{z_{\text {int }}}^{H} T(z) d z
$$

In addition, this paper discusses the effect on the smoke height and fire heat release rate of mounting one and two mechanical smoke vents. The smoke vent is $0.5 \mathrm{~m}$ long and $0.5 \mathrm{~m}$ wide, and its location is shown in Fig. 4. The computing grids used in this study are the maximum grid at 0.36 $\mathrm{m}$ and the minimum grid at $0.2 \mathrm{~m}$; thus, the total number of computing grid points is $150000(100 \times$ $100 \times 15)$.

\section{Results and discussion}

Case 1: Underground parking fire in actual state (without mechanical smoke ventilation)

To obtain a basis for comparison, the condition of an underground parking lot without a smoke extractor is simulated first. The simulated result in Fig. 5 shows that, when the first car on the upper left of the parking lot is the fire's origin, the smoke layer at the S1 monitoring point descends

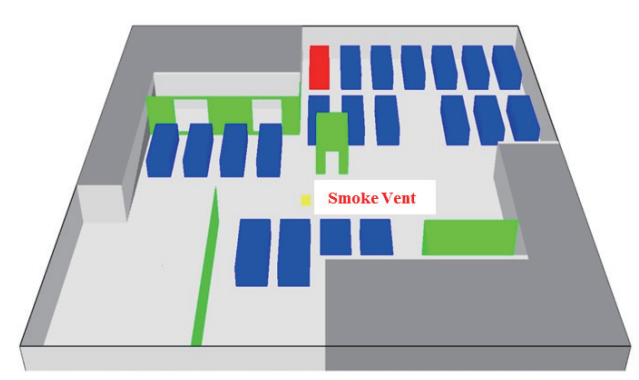

(a)

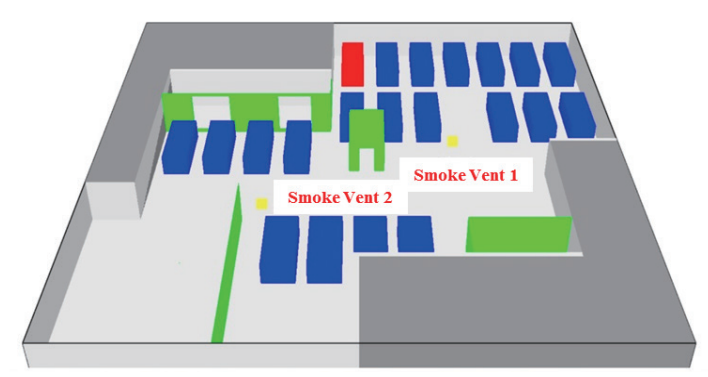

(b)

Fig. 4. (Color online) Location of smoke vents. (a) Case 2 and (b) Case 3.

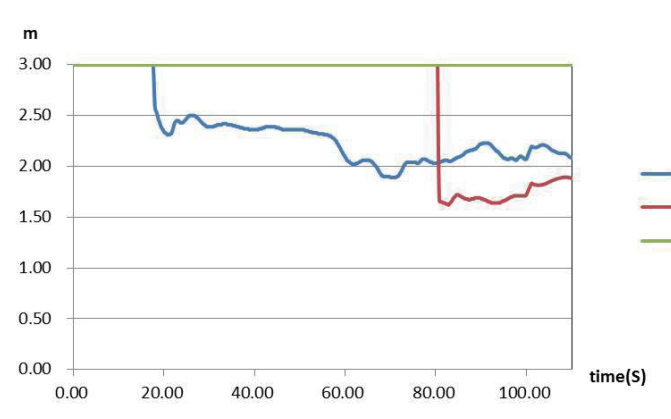

(a)

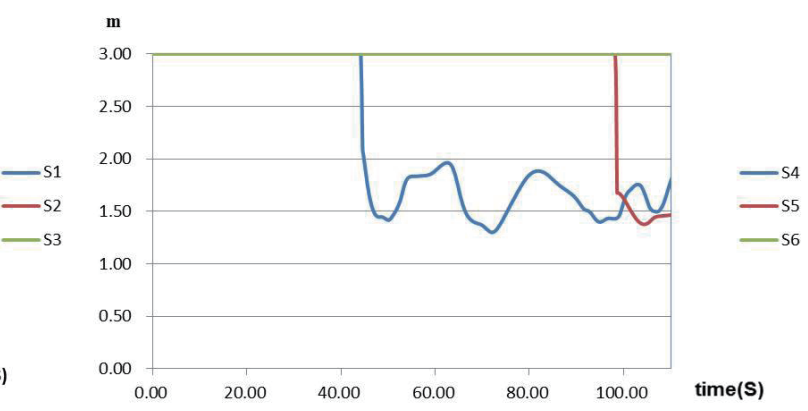

(b)

Fig. 5. (Color online) Analysis of smoke height without smoke vent (Case 1-1). 
to a height of about $2.3 \mathrm{~m}$ at $20 \mathrm{~s}$, and visibility is sufficient for escape, as most of the smoke layer accumulates near the fire's origin, and the fire has not yet spread. At $50 \mathrm{~s}$, the smoke layer begins to deposit near Exit 2, and the smoke height is about $1.5 \mathrm{~m}$. At $80 \mathrm{~s}$ of fire, the height of the neutral plane of the smoke layer at the $\mathrm{S} 1$ monitoring point is about $2 \mathrm{~m}$, the smoke layer at the $\mathrm{S} 2$ monitoring point descends to the height of about $1.6 \mathrm{~m}$, the fire begins to spread, and visibility for escape is severely influenced. At $100 \mathrm{~s}$, the smoke layer does not descend continuously, and the smoke height is $1.6-2 \mathrm{~m}$. However, as the fire has spread, the area of the smoke layer expands to the lane, thus severely obstructing escape.

Figure 6 shows the smoke deposit without a smoke vent when the first car on the lower left of the parking lot is on fire. The smoke layer begins to deposit at the S2 monitoring point under the effect of the smoke plume; however, as the smoke layer continues to diffuse horizontally, it stops depositing downward, and the smoke height is maintained above $2 \mathrm{~m}$. The smoke deposits at the $\mathrm{S} 4$ monitoring point at $40 \mathrm{~s}$, rapidly descends to $0.7 \mathrm{~m}$, and most of the dense smoke is discharged through Exit 2; thus the smoke height at S4 returns to $1.7 \mathrm{~m}$. However, the dense smoke begins to affect human sight if people look for the exit. The smoke layer diffuses to $\mathrm{S} 1$ at $60 \mathrm{~s}$, and the final smoke height is lower than $1.5 \mathrm{~m}$. Dense smoke diffuses to the monitoring points (S3, S5, and S6) near Exit 1 and the lane; however, because the lane is wide enough, the smoke height does not influence visibility.

Figure 7 shows the smoke deposit when the first car on the lower right of the parking lot is on fire. A smoke jet passes the S2 monitoring point before $20 \mathrm{~s}$, this result is identical to the previous

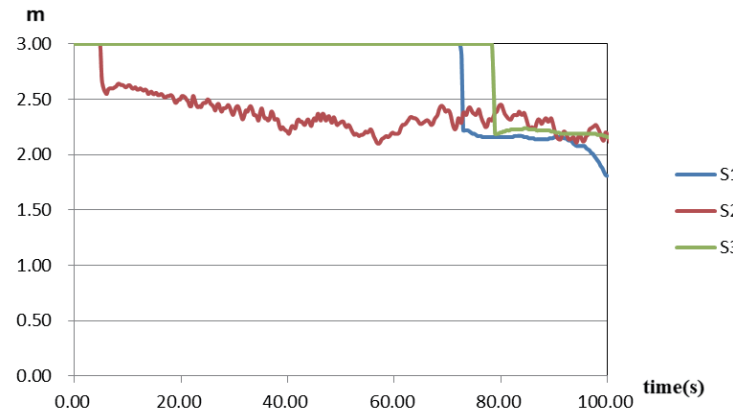

(a)

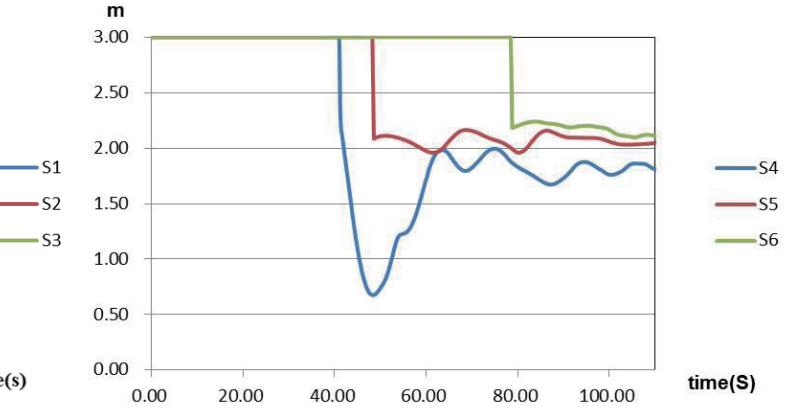

(b)

Fig. 6. (Color online) Analysis of smoke height without smoke vent (Case 1-2).

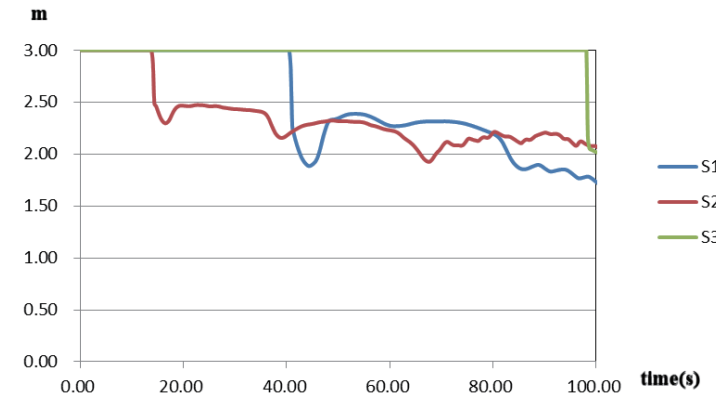

(a)

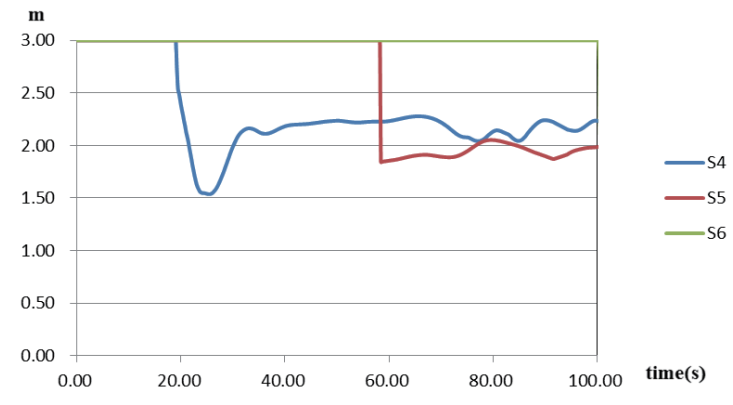

(b)

Fig. 7. (Color online) Analysis of smoke height without smoke vent (Case 1-3). 
case. As the S4 monitoring point is close to the fire origin, the smoke layer begins to deposit at 20 $\mathrm{s}$. The smoke begins to deposit at $\mathrm{S} 1$ at $40 \mathrm{~s}$, and because there is no mechanical smoke extraction, the final smoke layer is lower than $1.59 \mathrm{~m}$. As the fire's origin is on the right side of the parking lot, most of the dense smoke accumulates on the right and spreads to the aboveground floors via Exit 2. The stairs may cause a stacking effect due to the dense smoke, leading to heavier casualties. There is little dense smoke deposit at the left measuring point; thus the smoke height does not influence sight.

While the fire's origins are different in the fire simulation, as there is no enough fresh air imported, the car on fire is not burnt completely, and the maximum heat release rate of Case 1-1Case 1-3 shown in Fig. 8(a) is 1 MW.

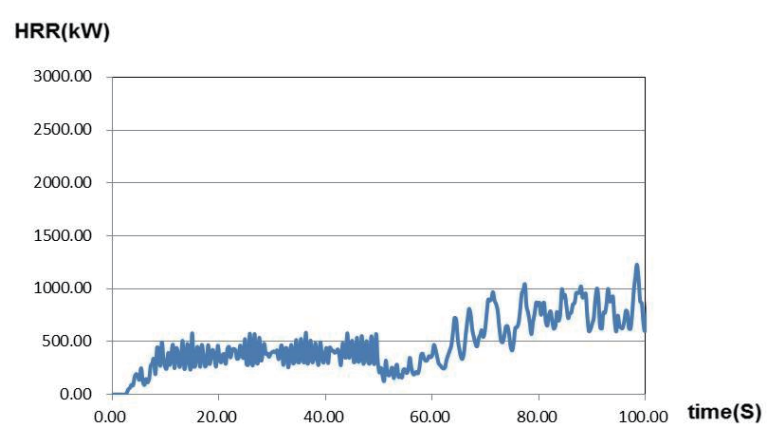

(a)

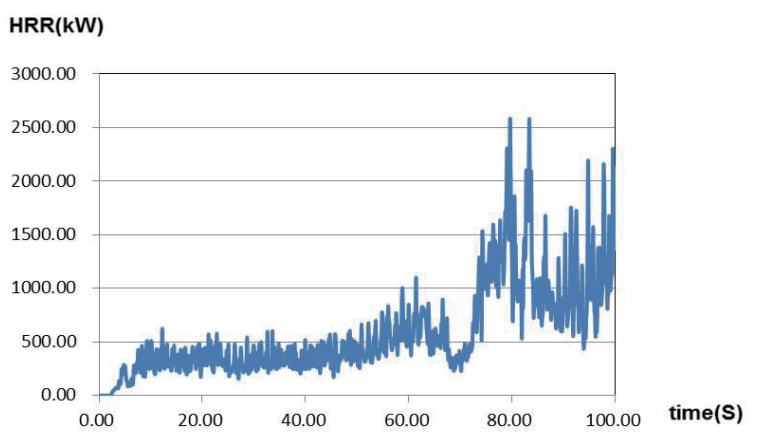

(c)

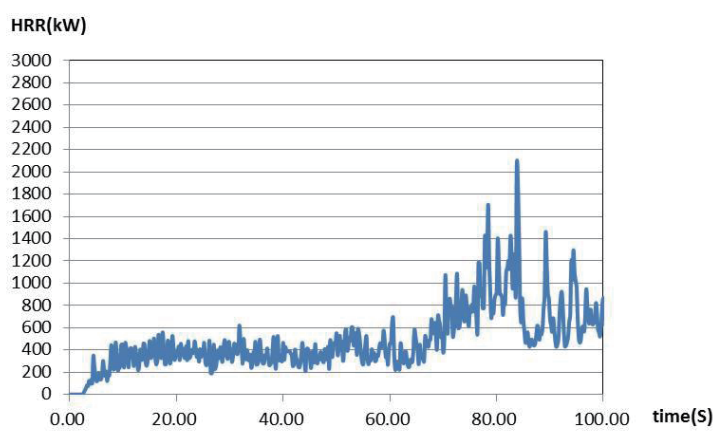

(b)

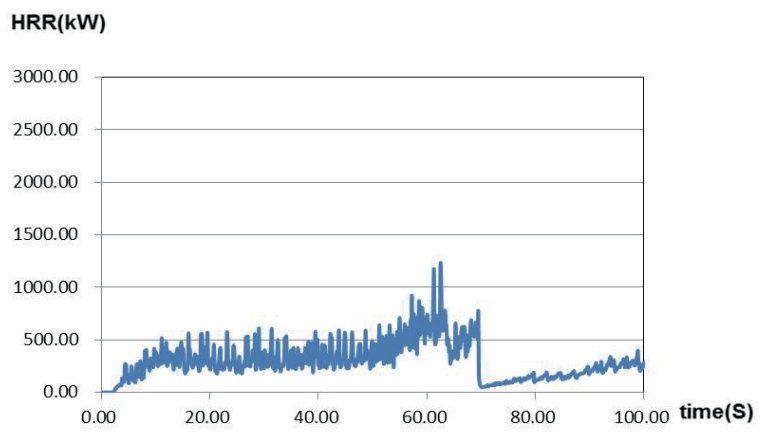

(d)

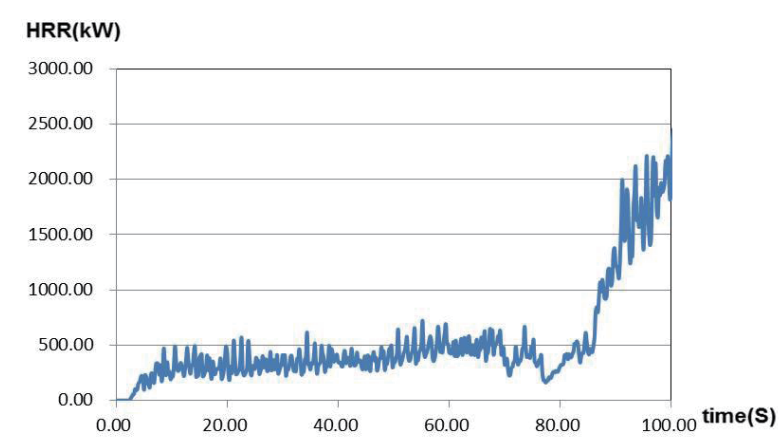

(e)

Fig. 8. (Color online) Fire HRR simulation results. 
Case 2: With one smoke vent

In this simulation, a mechanical smoke vent is mounted at the center of the underground parking lot. Figures 9-11 show the simulated results of the upper left, lower left, and lower right cars being on fire. When the fire occurs in the upper left car, the smoke layer deposition rate at the S1 monitoring point in the first $80 \mathrm{~s}$ is almost the same as case 1, meaning the smoke layer descends to $2 \mathrm{~m}$. At $100 \mathrm{~s}$, the smoke layer at the S1 monitoring point descends to $1.55 \mathrm{~m}$, which is lower than the smoke layer without smoke extraction, meaning that smoke extraction can accelerate the air flow in the underground space, the heat release rate is increased, and the dense smoke layer descends faster than in the case without smoke extraction. Figure $8(\mathrm{~b})$ indicates that the fire heat release rate

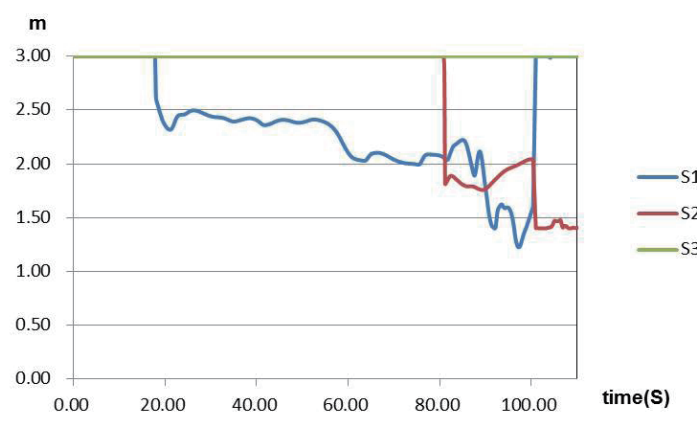

(a)

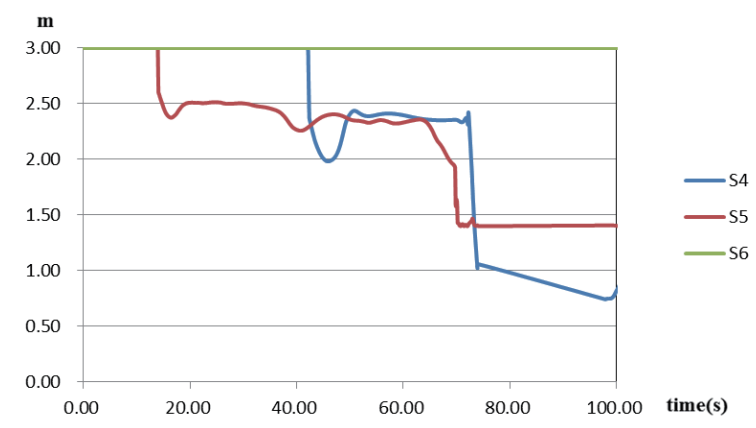

(b)

Fig. 9. (Color online) Analysis of smoke height with one mechanical smoke vent (Case 2-1).

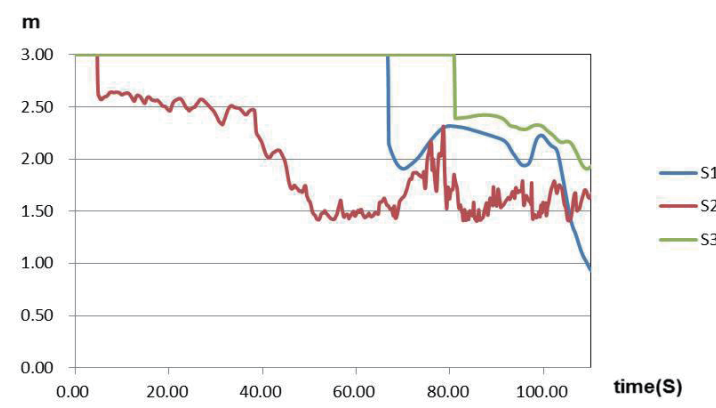

(a)

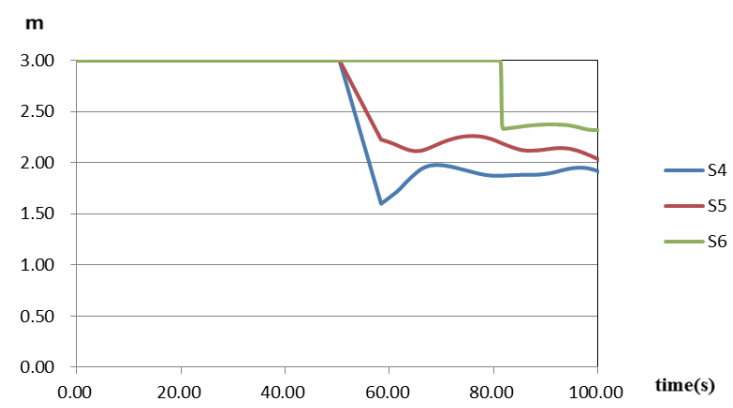

(b)

Fig. 10. (Color online) Analysis of smoke height with one mechanical smoke vent (Case 2-2).

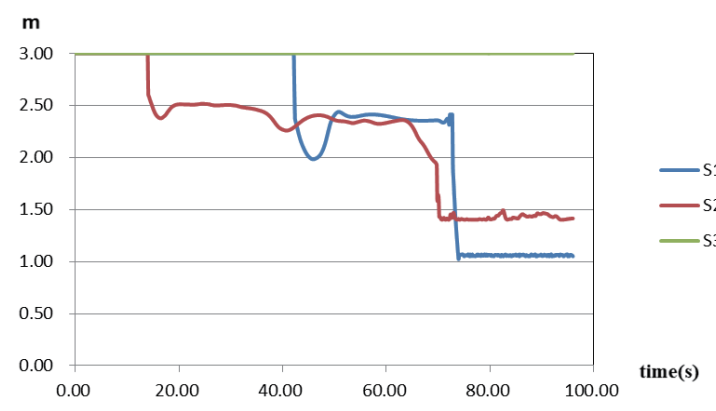

(a)

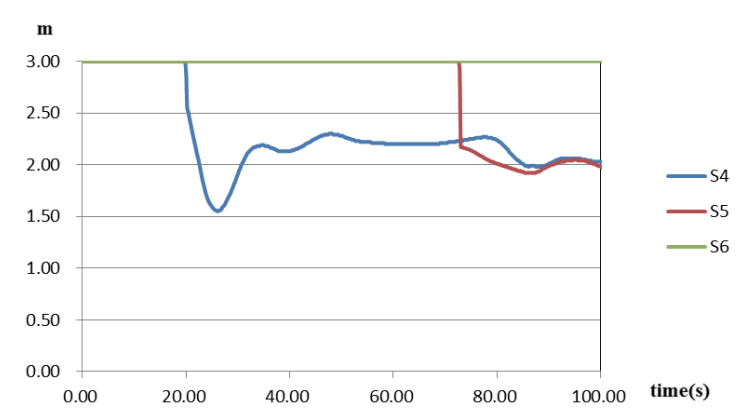

(b)

Fig. 11. (Color online) Analysis of smoke height with one mechanical smoke vent (Case 2-3). 
of Case 2-1 is close to Case 1 at the initial stage of the fire, but the fire heat release rate at the late stage of Case 2-1 exceeds 1.0 MW, which is higher than the value of Case 1, meaning fresh outside air is imported by the smoke exhaust system, which supports combustion. In addition, the smoke layer begins to deposit at the S2 monitoring point after $80 \mathrm{~s}$. The smoke layer is quite obvious and dense at the S4 monitoring point near Exit 2, and the smoke layer descends to $1.43 \mathrm{~m}$. When a smoke vent is mounted in the center, the dense smoke flow is more disorderly than in the case without smoke extraction, and the smoke layer descent is not retarded in some areas. At S5, the air flow resulting from the smoke vent attracts the dense smoke to diffuse to the left. The starting time of deposit at S5 is almost the same as S1, which is much earlier than the case without smoke extraction.

When the fire breaks out in the first car on the lower left of the parking lot, the black smoke generated by the fire is attracted by the mechanical smoke vent, and the smoke diffuses faster than the case without smoke extraction (Case 1). Furthermore, the fresh air imported by mechanical smoke extraction accelerates the fire, and the generation of dense smoke is greater than in Case 1; therefore, the dense smoke cannot be completely discharged from the smoke vent, and the dense smoke accumulates at Exits 1 and 2. Figure 9 is the smoke height analysis. The smoke layer at Exit 2 (S4 monitoring point) is lower than $1.5 \mathrm{~m}$, and the smoke height changes greatly, meaning the poor smoke extraction effect results in a turbulent stream. On the other hand, as the dense smoke is attracted by the mechanical smoke vent, it is deflected towards the right side (Exit 2). Therefore, the starting time of the smoke layer deposit at Exit 1 (S5 monitoring point) in this case is later than the case where the fire breaks out at the upper left car. When the fire breaks out in the first car on the lower right of the parking lot, the dense smoke soon reaches Exit 2 (S4 monitoring point); thus it deposits after $20 \mathrm{~s}$, and the smoke height is $1.5-2.0 \mathrm{~m}$. The smoke begins to deposit at Exit 1 (S5 monitoring point) after $70 \mathrm{~s}$; however, the smoke volume is increased as the heat release rate is increased by mechanical smoke extraction, and the smoke layer at $\mathrm{S} 2$ descends to $1.43 \mathrm{~m}$, which is lower than the smoke layer in the case without smoke extraction.

In the case of one smoke vent, the fire's origin has a significant effect on the fire's heat release rate. When the fire's origin is on the upper left, lower left, or lower right, the maximum heat release rate [Figs. $8(\mathrm{~b})-8(\mathrm{~d})]$ is $2.1,2.5$, and $1.0 \mathrm{MW}$, respectively. When the fire breaks out on the lower left, as the mechanical smoke vent is close to the fire's origin, the fresh outside air drawn in by the mechanical smoke extraction increases the fire's heat release rate. However, when the fire breaks out on the lower right, the fresh outside air cannot be imported into the fire scene, and the heat release rate is close to the case without smoke extraction; thus there is smoldering or extinguishing after $70 \mathrm{~s}$.

Case 3: With two smoke vents (symmetrically allocated)

This case discusses the effect on the smoke layer accumulation and heat release rate of having two mounted mechanical smoke vents in the underground parking fire. The mechanical smoke vents are located at the S1 and S2 monitoring points, and the total exhaust smoke level of the two smoke vents is the same as the previous case. Figures 12-14 show the simulation results of smoke layer accumulation when the fire breaks out in the upper left, lower left, or lower right cars. When the fire breaks out in the first car on the upper left, part of the dense smoke is exhausted from smoke vent 1 , thus reducing the descent speed of the smoke layer. The smoke height at the S1 monitoring point is stabilized at $2.1 \mathrm{~m}$ in the simulation, and the smoke layer at the $\mathrm{S} 2$ monitoring point begins to deposit $70 \mathrm{~s}$ before that, as the mechanical smoke extraction accelerates dense smoke flow. 


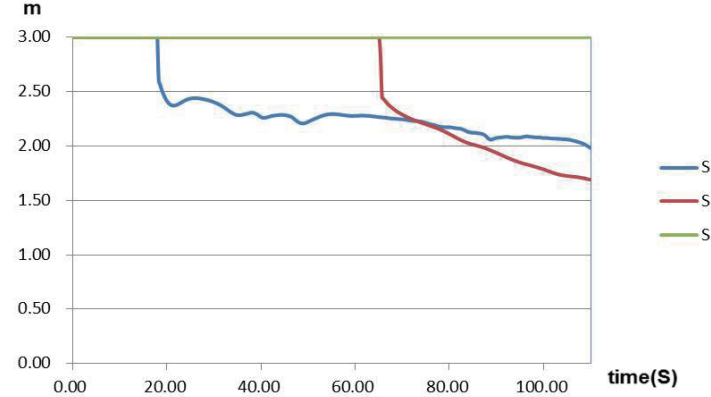

(a)

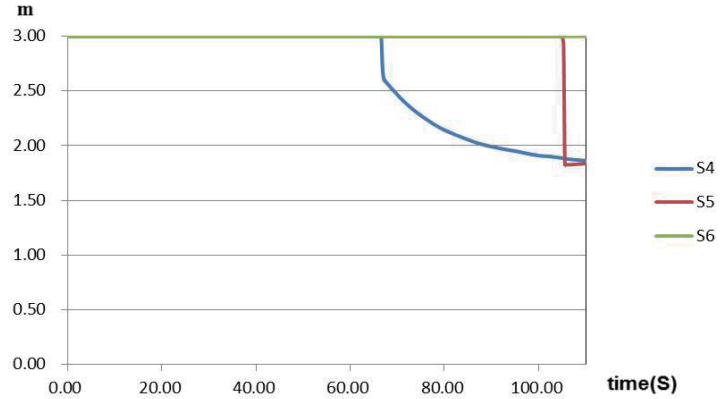

(b)

Fig. 12. (Color online) Analysis of smoke height with two mechanical smoke vents (Case 3-1).

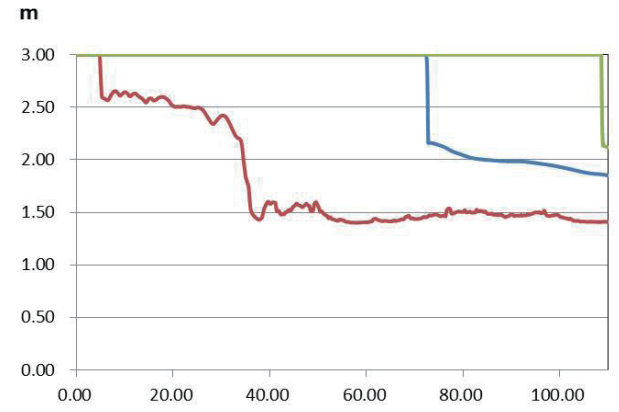

(a)

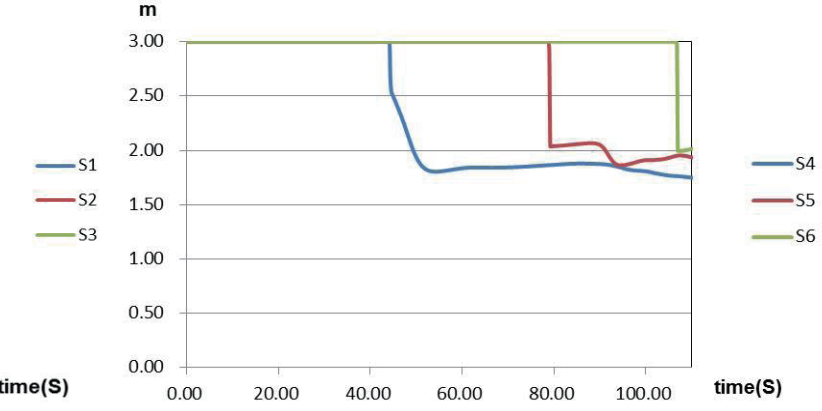

(b)

Fig. 13. (Color online) Analysis of smoke height with two mechanical smoke vents (Case 3-2).

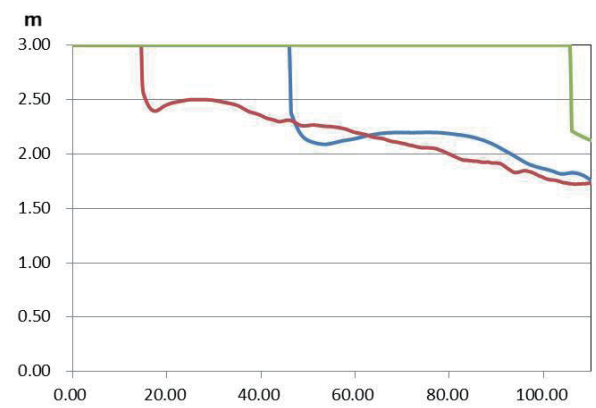

(a)

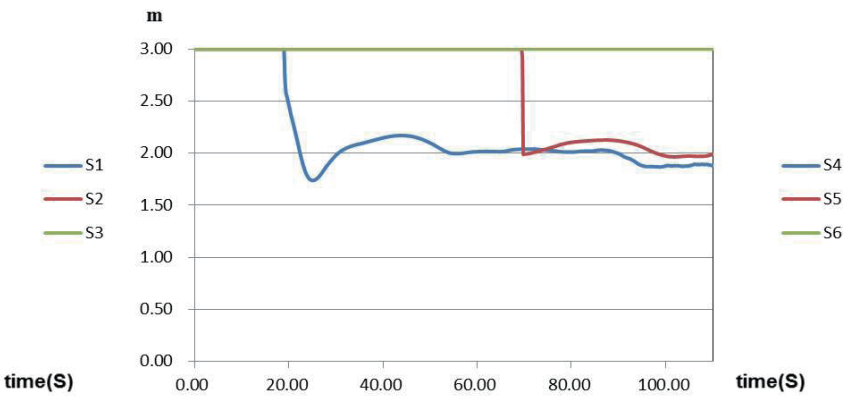

(b)

Fig. 14. (Color online) Analysis of smoke height with two mechanical smoke vents (average) (Case 3-3).

However, the smoke height is maintained at $1.7 \mathrm{~m}$, which is a little higher than the smoke height in Case 1. The smoke layers at S4 and S5 (Exit 2 and Exit 1) are maintained above 1.8-1.9 m; this result shows that the smoke layer in the case with two smoke vents is higher than the case without a smoke vent, which is very helpful for escape. However, according to the simulation results of Cases 1-3, the location and number of smoke vents can influence the volume of imported fresh outside air; thus the fire heat release rate is changed. Mechanical smoke extraction can increase the heat release rate, and the fire heat release rate is $2.0 \mathrm{MW}$ in the case with two mechanical smoke vents [Fig. 8(e)]. 
When a fire breaks out in the first car on the lower left of the parking lot, the dense smoke at the fire's origin is confined to the fire's origin; the smoke layer at S2 descends rapidly to about 1.5 $\mathrm{m}$. However, because the smoke vents continuously discharge the smoke, the smoke layer at S2 is maintained at $1.5 \mathrm{~m}$. Though S1 is far from the fire's origin and there is a smoke vent nearby, the smoke does not deposit until $72 \mathrm{~s}$, and the height is stabilized at about $1.8 \mathrm{~m}$. The smoke height at $\mathrm{S} 4$ is maintained at $1.7-1.8 \mathrm{~m}$. As the fire origin is close to the lane, the starting time of smoke deposit at S5 is earlier than in Case 3-1, and there is little smoke deposit at S6.

When the fire breaks out in the first car on the lower right of the parking lot, as the fire origin is fairly far away from the two smoke vents, the dense smoke diffuses uniformly, and the dense smoke begins to deposit at $\mathrm{S} 2$ and $\mathrm{S} 4$ at almost the same time. As the smoke is attracted by smoke vent 1 , the starting time of smoke deposit at S1 (47 s) is earlier than that at S5 (70 s).

\section{Conclusions}

Once a fire breaks out in an underground parking lot, which is a floor without an opening, the building structure is damaged. It is necessary to enhance the fire safety of underground parking lots so that people can be safely evacuated and fire extinguishing work can be smoothly performed. In this paper, we use FDS software for the analysis of simulated fires in underground parking lots. According to the results of this study, the effective layout of smoke vents can create the critical time required for escape and initial rescue. The smoke vent location is significantly correlated with smoke deposit. If the smoke vent is located near the fire, the imported outside air makes the fire and smoke spread quickly. For an underground parking lot smaller than $1000 \mathrm{~m}^{2}$, the present fire code does not require mounted smoke exhaust fans. However, the simulations show that an efficient layout of smoke vents (compared with one smoke vent for $500 \mathrm{~m}^{2}$ specified for smoke compartments) can effectively prolong escape time. The findings of this study can provide a reference for underground parking lots to install the smoke detection sensors for detecting smoke at early fire growing stages in the future.

\section{References}

1 C. J. Lee: Master's thesis, National Taiwan University of Science and Technology (2005).

2 H. Y. Chen and L. S. Wu: Fire Theories (Tingmao Publishing, Taipei, 2007).

3 C. C. Chung and W. F. Chiu: The Study of Disaster Prevention Strategies and Systems of Large Scale Underground Structures (Ministry of the Interior, Taipei, 2004).

4 X. G. Zhang, Y. C. Guo, C. K. Chan, and W. Y. Lin: Build. Environ. 42 (2007) 3466.

5 B. Mercia and M. Shipp: Fire Saf. J. 57 (2013) 3.

6 X. Deckers, S. Haga, N. Tilley, and B. Mercia: Fire Saf. J. 57 (2013) 22.

7 T. Korhonen and S. Hostikka: Fire Dynamics Simulator with Evacuation: FDS+Evac Technical Reference and User's Guide (VTT Technical Research Centre of Finland, Vuorimiehentie, 2010).

8 K. McGrattan, S. Hostikka, R. McDermott, J. Floyd, C. Weinschenk, and K. Overholt: Fire Dynamics Simulator Technical Reference Guide Volume 3: Validation (NIST Special Publication 1018-3, Baltimore, 2016).

9 M. L. Janssens and H. C. Tran: J. Fire Sci. 10 (1992) 528.

10 Y. P. He, A. Fernando, and M. C. Luo: Fire Saf. J. 31 (1998) 19. 